\title{
ADUBAÇÃO NITROGENADA NA CULTURA DO FEIJOEIRO
}

\author{
Ana Carla Ramos RABELO ${ }^{1}$ \\ Daynan Ferreira RIBEIRO ${ }^{1}$
}

Ramiro Machado REZENDE ${ }^{2}$

Eliana ALCANTRA ${ }^{3}$

Aurivan de Soares de FREITAS ${ }^{4}$

\begin{abstract}
${ }^{1}$ Graduandos do curso de Agronomia/UninCor - email: anacarla182@hotmail.com, daynan_fr@hotmail.com; ${ }^{2}$ Orientador e Professor Doutor do curso de Agronomia/UninCor - email: ramiromr@globo.com ${ }^{3}$ Co-orientadora e Professora Doutora do curso de Agronomia/UninCor- email: lialcantra @ yahoo.com.br ${ }^{4}$ Professor Doutor do curso de Agronomia/UninCor-email: aurivan.soares@ hotmail.com
\end{abstract}

Recebido em: 08/07/2016 - Aprovado em: 05/05/2017 - Disponibilizado em: 01/07/2017

\section{RESUMO:}

Sendo o nitrogênio um nutriente limitante para o crescimento, desenvolvimento e produção do feijoeiro, muitas dúvidas surgem quanto a dose, forma de aplicação, fonte de $\mathrm{N}$ e estádio em que a planta melhor responde a sua aplicação. Com isto, objetivou-se com essa revisão literária analisar experimentos e resultados de diversos autores afim de buscar respostas a essas duvidas. A principal resposta e que a adubação depende do manejo da área a ser implantada a cultura e que a melhor resposta do feijoeiro a aplicação de $\mathrm{N}$ e quando este e fornecido no inicio do seu ciclo, ate V4.

Palavras-chave: Feijão. Adubação nitrogenada. Phaseolus vulgaris. Nutriente. Fixação biológica.

\section{NITROGEN FERTILIZATION IN THE CULTURE OF THE BEAN}

\begin{abstract}
:
As the nitrogen is a limiting nutrient for growth, development and production of beans, many doubts appear about the dose, form of application, $\mathrm{N}$ source and which stage the plant responds better to application. With this, the objective of the literature review is analyze experiments and results of several authors in order to seek answers to these doubts. The main answer is that fertilization depends on the management of the area to be implanted the culture and the best bean response to $\mathrm{N}$ application is when this is provided at the beginning of its cycle, up to V4.

Keywords: Bean. Nitrogen Fertilization. Phaseolus vulgaris. Nutrient. Biological fixation.
\end{abstract}

\section{INTRODUÇÃO}

Historicamente, o feijão está entre os alimentos mais antigos. Alguns historiadores afirmam que foi encontrado a primeira vez no Peru e posteriormente levado às regiões mexicanas onde fora domesticado, cerca de 7000 a.C. Já outros afirmam que o feijão fora descoberto no México e depois disseminado pela América do Sul.
Também há relatos de outras variedades encontradas nos continentes asiático, africano e europeu e que são consideradas secundárias.

No Brasil, acredita-se que o cultivo de feijão começou a cerca de 2000 anos atrás, pois foram encontradas sementes de feijão em cavernas desse período.

Portanto, não é de hoje que o feijão está presente na mesa da população brasileira. 
Os grãos do feijão representam uma importante fonte proteica na dieta humana além dos conteúdos de carboidratos e minerais, especialmente o ferro. Além de sua importância nutricional, também é uma cultura de grande participação econômicasocial do país, por ser amplamente cultivado e pela mão-de-obra utilizada. Só no estado de Minas Gerais estima-se o uso de cerca 295.000 produtores.

Hoje, o Brasil se enquadra como o maior produtor e consumidor mundial de feijão. Tem como principal produtor o estado do Paraná, seguido em segundo lugar por Minas Gerais.

A área cultivada com feijoeiro no Brasil ficou em quarto lugar, perdendo somente para soja, milho e cana-de-açúcar, se destacando das culturas de café, trigo, entre outras. (IBGE, 2011)

Os tipos de feijão mais conhecidos no nacionalmente são: feijão preto, roxinho, fradinho, mulatinho, branco, rosinha, verde, carioca, entre outros e os mais consumidos pelos brasileiros são o carioca, preto e o roxinho. O feijão é também, responsável por um dos pratos mais famosos da culinária mundial, a feijoada.

Os estudos e pesquisas relacionados a essa cultura, tiveram avanço nos anos 50 quando a população brasileira cresceu significativamente e o mesmo não ocorreu com a produção deste grão gerando escassez desta leguminosa no mercado. Deste então se busca variedades mais resistentes e produtivas, assim como técnicas de aprimoramento do manejo desta cultura.

Muito se especula sobre as melhores formas de manejo e tratos de uma lavoura de feijoeiro, a fim de colher bons frutos, de qualidade, com custo baixo e garantindo produtividade. O feijoeiro é uma cultura que responde muito bem a tudo que lhe é fornecido, desta forma fica a dúvida de qual seria a melhor época e forma de aplicação de nitrogênio que apresente o melhor custo benefício à lavoura. Sendo o Nitrogênio o nutriente exigido em maior quantidade pelas plantas, por ser responsável pelo seu crescimento vegetativo, produção de novas células e tecidos, formação de clorofila e também o principal custo de produção de uma lavoura. Devendo o produtor sabe qual seu melhor manejo: dose, época, fonte de aplicação afim de não desperdiçar adubo e dinheiro. De acordo com Almeida et al. (2000), o feijoeiro é uma planta de ciclo curto exigente em nutrientes, devido ao pequeno e pouco profundo sistema radicular. Por isso, é fundamental que os nutrientes sejam colocados à disposição da planta em quantidades, tempo e locais adequados.

Por outro lado, excesso de nitrogênio além de aumentar os custos de produção, pode causar danos as plantas do feijoeiro, como crescimento vegetativo acelerado, podendo prejudicar os estágios reprodutivos retardando a floração e pode ter o ciclo de 
vida reduzido, diminui a resistência da plantas à doenças, desequilibra o balanço entre os nutrientes, além de também se tornar um grande poluente do meio ambiente através da contaminação de lençóis freáticos, rios e lagos, sendo seu uso racional de grande importância para a cultura, o produtor e o planeta.

Assim objetivou-se com essa revisão direcionar o melhor manejo da adubação nitrogenada no feijoeiro através de diversos experimentos estudados, buscando a fonte, a dosagem e a época do fornecimento de $\mathrm{N}$ ao feijoeiro que garanta melhor produtividade e melhor custo beneficio ao produtor.

\section{REVISÃO DE LITERATURA}

O feijoeiro é uma cultura em ascendência e muitos estudiosos e pesquisadores se dedicam a entender melhor seu cultivo (RIBEIRO et al., 1999).

\section{Classificação botânica do feijão}

Botanicamente, o feijoeiro pertence ao Reino Plantae, Classe Magnoliopsida, Ordem das Rosales, à Família Leguminosae ou Fabaceae, ao Gênero: Phaseolus L. e à Espécie: Phaseolus vulgaris L. (RIBEIRO et al., 1999).

\section{Dados Gerais}

Graças às suas comprovadas propriedades nutritivas e terapêuticas, o feijão é altamente desejável como componentes em dietas de combate à fome e à desnutrição. $\mathrm{O}$ feijão do grão tipo carioca é aceito em praticamente todo o Brasil, por isso que 53\% da área cultivada é semeada com este tipo grão (EMBRAPA, 2002).

O cultivo dessa leguminosa é bastante difundido em todo o território nacional, no sistema solteiro ou consorciado com outras culturas. É reconhecida como cultura de subsistência em pequenas propriedades, muito embora tenha havido, nos últimos 20 anos, crescente interesse de produtores de outras classes, adotando tecnologias avançadas, incluindo a irrigação e a colheita mecanizada (EMBRAPA, 2002).

O Brasil destaca-se como o maior produtor mundial de feijão. $\mathrm{O}$ estado de Minas Gerais é o segundo maior produtor nacional, com aproximadamente $15 \%$ da produção total. O país é também o maior consumidor mundial de feijão-comum, com um consumo estimado em aproximadamente $16 \mathrm{Kg} / \mathrm{ano}$. Vale ressaltar que este valor é inferior à média estimada na década de 1970 , quando o consumo era de aproximadamente $25 \mathrm{Kg} /$ ano o que, contudo, não ameaça o país maior consumidor dessa leguminosa no mundo (CIF, 2008).

Segundo a Conab (2016), a primeira safra de feijão de 2016, ou safra de verão ou safra das aguas, plantada em meados de outubro a dezembro, com colheita de janeiro a março, abrangeu mais de 1 milhão de 
hectares, com uma produção que ultrapassou 1,2 milhão de toneladas, destacando o Paraná se como maior produtor da primeira safra e Minas Gerais em segundo lugar produzindo 198 mil toneladas.

Mesmo sendo uma cultura de grande participação na agricultura familiar, hoje em dia, já se usa cultivar de feijoeiro com alta tecnologia, como irrigação, máquinas colhedoras, mas existe sempre um risco ao se plantar o feijoeiro. No Brasil, $80 \%$ da produção é proveniente do cultivo das "águas" e da "seca", ambos de elevado risco. No caso do cultivo nas águas, o risco está na colheita devido ao período chuvoso comprometendo a possibilidade de colheita assim como sua qualidade. Já no período da seca, o risco encontra-se na deficiência hídrica nas fases críticas da cultura como floração, formação das vagens e enchimento de grãos. (BORÉM e CARNEIRO, 2015). Além disso, o feijoeiro é suscetível a numerosas pragas, com por exemplo: lagartarosca (Agrotis ípsilon), lagarta-elasmo (Elasmopalpus lignosellus), vaquinha (Diabrotica speciosa), larva-minadora (Liriomyza huidobrensis), lagarta das folhas (Pseudoplusia includens), mosca-branca (Bemisia tabaci), tripes, ácaros, percevejos (QUINTELA; BARBOSA, 2015) e doenças como: mancha angular, antracnose, ferrugem, mofo branco e murcha de fusarium (PAULA JUNIOR et al., 2015).

\section{O Feijoeiro}

O feijão é uma planta anual, herbácea, trepadora ou não, de crescimento determinado e indeterminado. O sistema radicular é formado de uma raiz principal ou primária, da qual se desenvolvem as raízes secundárias e terciárias lateralmente (BORÉM e CARNEIRO, 2015).

Caule do feijoeiro é herbáceo, constituído de um eixo principal, contendo os nós e entrenós. O primeiro nó aquele onde ocorre a inserção dos cotilédones; o segundo, das folhas primárias. $\mathrm{O}$ terceiro, da primeira folha trifoliada e assim sucessivamente (BORÉM e CARNEIRO, 2015).

Quanto às folhas, o feijoeiro apresenta dois tipos de folhas: folhas simples e folhas compostas. As simples são duas e as primeiras a serem formadas, aparecem no segundo nó do caule e são formadas dentro da semente durante a embriogênese e caem antes do completo desenvolvimento da planta. Já as folhas compostas são constituídas de três folíolos, com disposição alternada, e definitivas (CIF, 2008).

As flores podem ser do tipo rácemo axilar (para crescimento indeterminado) e rácemo terminal (no hábito de crescimento determinado) e são compostas de três partes principais: um eixo composto de pedúnculo e ráquis, as brácteas e os botões florais (CIF, 2008). A autopolinização é favorecida no Phaseolus vulgaris L., pois as anteras estão situadas no mesmo nível do estigma. Quando 
ocorre a deiscência das anteras, os grãos de polen caem diretamente sobre o estigma (SANTOS et al. 2015).

O fruto é um legume (vagem), de um só carpelo, seco, deiscente, zigomorfo, geralmente alongado e comprimido, com as sementes em uma fileira central, cuja deiscência é provocada durante a secagem do fruto maduro. A vagem é aplanada, reta ou encurvada, com ápice verde uniforme a arroxeada ou quase negra podendo apresentar listras e pintas em alguns cultivares (SANTOS et al., 2015).

A semente pode ter forma arredondada, elíptica, reniforme ou oblonga, de cores que vai do branco ao negro, passando por quase todas as cores, podendo ser uniforme, pintada, listrada ou manchada (CIF, 2008).

\subsubsection{Fenologia do Feijoeiro}

Normalmente a forma de verificar o estádio de desenvolvimento do feijoeiro, é contar o número de dias desde a semeadura. Porém, devido a fatores genéticos e ambientais, esses dias podem se prolongar ou adiantar durante o desenvolvimento da planta, como, por exemplo, um feijoeiro de sequeiro no inverno do sul de Minas Gerais, onde a temperatura é baixa, acarreta o atraso de todas as fases de desenvolvimento da planta (SANTOS et. al, 2015).

Com isso, usa-se uma escala baseada nas alterações morfológicas e fisiológicas que a planta sofre durante o seu ciclo, assim indica com mais precisão os estádios de desenvolvimento da planta, sem depender das variações genéticas e ambientais (SANTOS et. al, 2015).

Essa escala divide o ciclo do feijão em fases vegetativa e reprodutiva. Essas fases são subdivididas em dez etapas: Fase vegetativa (V): V0, V1, V2, V3 e V4; fase reprodutiva (R): R5, R6, R7, R8 e R9 (FERNANDEZ et al., 1985 apud SANTOS et al., 2015).

$\mathrm{O}$ ciclo vegetativo começa quando a semente é colocada em condições para germinar até o aparecimento do primeiro botão floral, nos cultivares de ciclo determinado ou da primeira inflorescência nos cultivares de crescimento indeterminado. (SANTOS et al., 2015).

Fase vegetativa segundo Santos et al., (2015): V0: etapa da germinação - dia da semeadura em solo úmido, ou, no caso de semeadura em solo seco, ao dia que ocorre a primeira chuva ou irrigação, ou seja, ao dia em que há condições de umidade para a germinação; V1: etapa da emergência surgimento, na superfície do solo, do hipocótilo encurvado, arrastando os cotilédones, presos no primeiro nó da haste principal e vai até a separação e abertura das folhas primárias; V2: inicia com a abertura das folhas primárias, que são unifolioladas e encontram-se em posição horizontal. Nessa fase os cotilédones murcham e a primeira folha trifoliolada, inicia 
sua abertura e dura cerca de quatro dias. A cultura encontra-se na fase V2 quando $50 \%$ das plantas estão com as folhas primarias completamente abertas. V3: inicia com a primeira folha trifoliolada totalmente aberta e $50 \%$ da lavoura apresenta esse aspecto. O término deste estádio leva de cinco a nove dias quando a segunda folha trifoliolada se encontra em pleno crescimento e a terceira folha trifoliolada se abre, posicionando-se sob a primeira folha trifoliolada. V4: se inicia com a terceira folha trifoliolada completamente aberta, e a cultura está nesse estádio quando $50 \%$ das plantas estão nessas condições. Nessa fase começa a surgir as primeiras hastes secundárias originadas das gemas auxiliares dos nós inferiores, e a mais desenvolvida já exibe a primeira folha trifoliolada. Esta etapa leva de sete a quinze dias e termina quando ocorre o surgimento do primeiro botão floral nos cultivares de hábito determinado, ou da primeira inflorescência nos cultivares de hábito indeterminado. Até atingir esse estádio, a haste principal pode desenvolver-se emitindo outras folhas trifolioladas.

A fase reprodutiva pode ser dividida em R5: o término do estádio V4, e também o término do período vegetativo e início da fase reprodutiva e da primeira etapa desta fase. Esta etapa estende-se até a abertura da primeira flor, durando cerca de dez dias; R6: floração - se inicia com a abertura da primeira flor e termina com a queda da corola, expondo a primeira vagem em início de desenvolvimento, durando cerca de quatro a cinco dias; R7: formação das vagens começa com a exposição da primeira vagem até atingir seu crescimento máximo longitudinal, durante cerca de oito dias; R8: enchimento das vagens - começa com a primeira vagem atingindo seu tamanho máximo, e corresponde ao período em que as sementes apresentam o crescimento mais pronunciado, até atingir seu tamanho final, pode durar de dezoito a vinte e quatro dias dependendo da cultivar. O fim desta etapa é marcado pela mudança de cor dos grãos de verde para a cor característica da cultivar; R9: maturação - compreende o início da descoloração das vagens, amarelecimento e queda das folhas, até a seca total da planta. Ocorre em cerca de 15 dias. É nessa fase que a semente perde umidade e o teor de água das sementes é de cerca $15 \%$, quando se deve realizar a colheita (SANTOS et. al, 2015).

\subsection{Adubação}

Segundo Vieira et al. (2015), são conhecidos dezesseis elementos essenciais para a vida da planta. Destes, carbono (C), oxigênio $(\mathrm{O})$ e hidrogênio $(\mathrm{H})$ são obtidos do ar e da água. Os demais treze nutrientes são adquiridos pelas raízes do solo, ou pelas folhas.

Os macronutrientes são aqueles com maior concentração nas plantas, nitrogênio $(\mathrm{N})$, Fósforo (P) e Potássio (K), sendo N e K 
os mais absorvidos pela planta. Embora a absorção de $\mathrm{P}$ seja menor, não se dispensa a adubação fosfatada pois os solos brasileiros são deficientes neste nutriente. Também macronutrientes são o cálcio $(\mathrm{Ca})$, magnésio $(\mathrm{Mg})$ e enxofre (S) e normalmente fornecidos por adubos e corretivos de solo. Os micronutrientes, exigidos em menores quantidades pela planta, porém não menos importante que os macro, são: Cloro $(\mathrm{Cl})$, Ferro (Fe), Manganês (Mn), Zinco (Zn), Boro (B), Cobre $(\mathrm{Cu})$, e Molibidênio (Mo) (VIEIRA et al., 2015).

A prática da adubação depende, de vários fatores, os quais devem ser previamente analisados no sentido de aconselhar os agricultores a praticarem uma adubação mais adequada, quanto aos aspectos agronômico, obtendo maior eficiência dos fertilizantes e econômico, resultando em maior renda líquida ao produtor (EMBRAPA, 2002).

Uma recomendação de adubação que atenda a estes princípios deve ser fundamentada em: resultados de análises de solo complementada pela análise foliar da planta; análise do histórico da área; conhecimento agronômico da cultura; comportamento ou tipo de cultivar; comportamento dos fertilizantes no solo; disponibilidade de capital do agricultor para aquisição de fertilizantes; expectativa de produtividade. Portanto, a recomendação de adubação para o feijoeiro, bem como para qualquer outra cultura, depende da análise cuidadosa de todos esses fatores, ressaltando que não existe uma regra geral a seguir nas recomendações de adubação (EMBRAPA, 2002).

Quanto à cultura do feijoeiro, a quantidade de fertilizantes varia de acordo com a época de plantio, quantidade e tipo de resíduo deixado na superfície do solo pela cultura anterior, e com a expectativa de rendimento. Geralmente, varia de 60 a 150 $\mathrm{Kg} / \mathrm{ha}$ de nitrogênio, sendo recomendado a aplicação parcelada em duas vezes; de 60 a $120 \mathrm{~kg} / \mathrm{ha}$ de $\mathrm{P}_{2} \mathrm{O}_{5}$, dependendo, evidentemente, do teor disponível de fósforo no solo, das condições de risco e da expectativa de rendimento de grãos e de 30 a $90 \mathrm{Kg} / \mathrm{ha}$ de $\mathrm{K}_{2} \mathrm{O}$, e a fonte de potássio, na maioria da vezes, é o cloreto de potássio com concentração de $60 \%$ de $\mathrm{K}_{2} \mathrm{O}$ (EMBRAPA, 2002).

Segundo Calonego (2010), o crescimento do feijoeiro é limitado pelo nutriente nitrogênio $(\mathrm{N})$ devendo este, ser fornecido em dosagem satisfatória para boa condução da lavoura.

\subsubsection{Nitrogênio no feijoeiro}

O nitrogênio é o nutriente exigido em maiores quantidades pela cultura do feijoeiro. A resposta à sua aplicação depende da dose aplicada e da época de sua aplicação (MEIRA et al., 2005). 
Segundo Vieira et al., (2015), a análise de solo não avalia com precisão a disponibilidade de $\mathrm{N}$ para a planta devido a complexidade de reações de $\mathrm{N}$ no solo. Neste caso, aconselha-se o uso da análise foliar da planta. Porém, sendo o feijoeiro uma cultura de ciclo rápido, ao receber a resposta do laboratório, o ciclo do feijoeiro já está adiantando e talvez a aplicação de $\mathrm{N}$ não seja mais eficaz.

$\mathrm{Na}$ produção de sementes, o uso de adubos nitrogenados pode beneficiar a produtividade e a qualidade da sementes, pois afeta a formação do embrião e dos órgãos de reserva (BARBOSA et al., 2011).

Vieira et al., (2015), diz que a atmosfera é rica em $\mathrm{N}_{2}$ (78\%), porém esse $\mathrm{N}$ não está disponível para a planta. Uma forma desse $\mathrm{N}$ chegar ao solo é por meio de descargas elétricas. Esse $\mathrm{N}$ originado da queima de combustíveis fosséis também chega ao solo, principalmente por chuvas, podendo contribuir com 3 a $5 \mathrm{Kg} / \mathrm{ha}$ de $\mathrm{N}$ por ano em áreas agrícolas não poluídas. Áreas vizinhas a grandes confinamentos de gado, essa contribuição pode aumentar para 40 a 50 $\mathrm{Kg} / \mathrm{ha}$. A simbiose com certas bactérias (rizóbios), pode fazer com que as leguminosas como feijão, aproveitem $\mathrm{o} \mathrm{N}_{2}$ presente no espaço poroso do solo. A fixação biológica do $\mathrm{N}$ (FBN) pode contribuir, em média, com $40 \%$ do $\mathrm{N}$ adquirido pelo feijoeiro.

Para conseguir fornecer $\mathrm{N}$ em dose satisfatória ao feijoeiro, deve-se utilizar fertilizantes, Vieira et al. (2015) cita como os principais fertilizantes utilizados no Brasil: ureia: custo baixo por unidade de $\mathrm{N}$, baixa corrosividade, alta solubilidade em água e alta absorção pelas folhas, porém é sujeita a perdas de $\mathrm{N}$ por volatilização da amônia $\left(\mathrm{NH}_{3}\right)$; sulfato de amônio: adubo que mais acidifica o solo, porém só ocorre volatilização de NH3 se aplicado com água alcalina (fertirrigação) ou sobre solo alcalino. Apresenta um preço elevado por unidade de $\mathrm{N}$, mas, se o $\mathrm{S}$ for aproveitado pela nutrição da planta, pode se tornar uma alternativa viável; nitrato de amônio: apresenta $\mathrm{N}$ na forma nítrica e amoniacal. É bastante solúvel em água e tem efeito acidificante semelhante ao da ureia.

Em relação ao nitrogênio, as dúvidas vão desde reações e mecanismos controladores da disponibilidade do $\mathrm{N}$ no solo, características e reações no solo das diferentes fontes de nitrogênio, até à prática da adubação, quanto a fontes, doses, métodos de aplicação, época mais adequada de aplicação durante o ciclo da cultura e a necessidade de seu parcelamento e, sobretudo, quanto aos seus aspectos econômicos. Estas técnicas de manejo de adubação, ainda são a melhor estratégia utilizada para maximizar a eficiência de uso do nitrogênio e permitir aos produtores obterem máximo retorno econômico do uso de fertilizantes (EMBRAPA, 2002). 
Vieira et.al (2015) afirma que não existe receita de bolo para adubação nitrogenada do feijoeiro, pois vários fatores podem influenciar a resposta da cultura à adubação nitrogenada: tempo de cultivo da gleba, tipo de solo, sistema de cultivo, tempo de condução do plantio direto, rotação de culturas, período do ano (chuvoso ou seco), produtividade esperada, adubação com $\mathrm{S}$, população de rizóbios do solo e potencial de FBN do cultivar. Existem dois tópicos que podem ser levados em consideração para avaliar a dosagem de $\mathrm{N}$ a ser fornecida: resultado de pesquisas - fazer pesquisas e obter resultados afim de conhecer a melhor forma, dose e época de fornecimento de $\mathrm{N}$ que a planta respondeu melhor produtividade esperada - quanto maior a produtividade de grãos desejada, maior a quantidade de $\mathrm{N}$ exigido pelo feijoeiro. Para cada tonelada de grãos produzidos, o feijoeiro acumula cerca de $50 \mathrm{Kg} / \mathrm{ha}$ de $\mathrm{N}$ na parte aérea - histórico da gleba e informações sobre a cultivar.

Malavolta (1979), apud Gerlach (2013), comenta que o $\mathrm{N}$ aplicado na dosagem recomendada ao feijoeiro, colabora para a decomposição da matéria orgânica, promove rápido crescimento, aumento da área foliar e do teor de proteína nas sementes.

$\mathrm{O}$ feijoeiro pode obter esse $\mathrm{N}$ através do solo, por meio da decomposição da matéria orgânica, através da aplicação de adubos nitrogenados e através da fixação biológica através dos rizóbios (HUNGRIA et al., 1997; MERCANTE et al., 1999 apud PELEGRIN, 2009).

A combinação do feijoeiro com as bactérias do grupo dos rizóbios é uma alternativa para substituir a adubação nitrogenada, total ou parcialmente (Grange et al. 2007, Pelegrin et al. 2009, Tozlu et al. 2012 apud Bertoldo et al. 2015). Porém, Matoso e Kusdra (2014) não encontraram resultados positivos quanto à inoculação do feijoeiro com Rhizobium tropici, quanto ao crescimento da planta, nodulação e fixação biológica de nitrogênio e que a complementação com molibdênio colabora para elevar a massa de nódulos formados por rizóbios nativos.

É necessário o correto manejo do nitrogênio, pois este também é um nutriente que pode se perder facilmente seja pelo processo de lixiviação, volatilização ou desnitrificação (SALGADO et al., 2012). Outro problema na aplicação de $\mathrm{N}$ na cultura é a fitotoxidez devido a quantidade de fertilizante nitrogenado fornecido via foliar, portanto é importante escolher a fonte do nutriente, o tipo de bico, a vazão e o horário da aplicação (ALMEIDA et al., 2000). Segundo Veira et. al., (2015), a ureia pode ser fornecida na folhagem do feijão em préfloração, com aproveitamento de até $80 \%$ do N. Usar no máximo 5\% de concentração de ureia na solução afim de evitar necroses nas folhas e ultilizar calda de 200 a $300 \mathrm{~L} / \mathrm{ha}$. 
Procurando a melhor dose de $\mathrm{N}$ a ser aplicado e a melhor fase fenológica da planta que responde melhor à disponibilidade deste nutriente, Binotti et al. (2009), conduziram um experimento na UNESP, município de Selviria (MS) durante o outono-inverno de 2005, irrigado quando necessário, com delineamento em blocos casualizados, em esquema fatorial $3 \times 5 \times 2$, constituído por três fontes de nitrogênio (ureia, sulfato de amônio e misto - metade $\mathrm{N}$ da ureia e metade $\mathrm{N}$ do sulfato de amônio), cinco doses de $\mathrm{N}$ (0, 50, 100, 150 e $200 \mathrm{Kg} / \mathrm{ha}$ ), aplicados em duas épocas: semeadura e parcelada (1/3 semeadura e $2 / 3$ na fase V4), com quatro repetições. Obtiveram resultado significativo no aumento de numero de vagens proporcionalmente ao aumento do $\mathrm{N}$ aplicado. No entanto, no quesito de modo ou fonte de $\mathrm{N}$ não houve diferença para número de vagens. $\mathrm{O}$ número de grãos por vagem também não teve diferença entre os tratamentos, muito provavelmente, por ser mais uma questão genética da cultivar. Porém, a produtividade com sulfato de amônio foi maior do que quando se usou ureia, entretanto, devido ao custo mais elevado do sulfato de amônio, este não seja o tratamento mais economicamente viável. Em relação ao parcelamento do nitrogênio também não houve resposta significativa, sendo que a aplicação total na semeadura apresentou o melhor custo/benefício.
Filho et al. (2007), demonstraram que esses resultados em relação a dosagem de $\mathrm{N}$ aplicados a cultura podem variar entre as cultivares do feijoeiro. Utilizou os cultivares Pérola e IAC Una, em sistema de plantio direto, na região de Ribeirão Preto - SP, com diferentes dosagens de $\mathrm{N}$ aplicados em cobertura $(0,50,100,150 \mathrm{~kg} / \mathrm{ha})$. A cultivar Pérola apresentou maior vulnerabilidade entre as dosagens de N, aumentando proporcionalmente sua produtividade e número de grãos por planta conforme houve aumento da disponibilidade do nutriente.

Salgado et al., (2012) também avaliaram diferentes variedades do feijoeiro em relação a aplicação de N. Foram estudados doze cultivares de feijoeiro: BRS Grafite, IAC Carioca Ete, IAC Uma, Safira, BRS Marfim, CNFC 10406, Princesa, IAC Centauro, IPR Saracura, IPR Colibri, IAC Diplomata e BRS Esplendor, em dois experimentos simulando alto e baixo teor de nitrogênio. No experimento com estresse de $\mathrm{N}$, foi aplicado somente $20 \mathrm{Kg} / \mathrm{ha}$ na semeadura, sendo o nutriente proveniente da adubação fosfatada e no segundo experimento, onde o ambiente para a cultura foi sem estresse de $\mathrm{N}$, foi aplicado $120 \mathrm{~kg} / \mathrm{há}$ de $\mathrm{N}$, sendo $20 \mathrm{~kg} / \mathrm{ha}$ aplicados na semeadura proveniente da adubação fosfatada, e $100 \mathrm{~kg} / \mathrm{ha}$ na forma de ureia, aplicados em cobertura e parcelados, sendo a primeira aplicação 15 DAE e a segunda 30 DAE. Obteve resultados expressivos quanto a produtividade de grãos, 
tendo sete variedades respondido de forma positiva e uma cultivar de forma negativa, possivelmente devido a um maior desenvolvimento vegetativo em presença do $\mathrm{N}$, em detrimento da fase reprodutiva. Salgado et al., concluiu que as variedades mais adaptáveis e mais responsivas a adubação com $\mathrm{N}$ foram BRS Grafite e Princesa, pois foram eficazes em utilizar o nitrogênio mesmo em concentrações baixas quanto em níveis ideias.

Santi et al. (2006) procuraram obter respostas em relação ao parcelamento adequado da adubação nitrogenada para o feijoeiro em sistema de plantio convencional. Implantou em Santa Maria - RS, as cultivares Pérola e TPS Nobre, adubando com ureia em cobertura a dose de $85 \mathrm{Kg} / \mathrm{ha}$ em uma única aplicação aos 14, 21, 28 e 35 DAE, e nos parcelamentos: $30 \%+70 \%, 50 \%+50 \%, 70 \%$ $+30 \%$ da dose aplicadas nas épocas citadas. Como resultado, os autores puderam perceber que a cultivar TPS Nobre apresentou potencial produtivo maior que a cultivar Pérola, porem no peso de cem grão a cultivar Pérola liderou, mostrando ser seu grão mais pesado. Quanto ao parcelamento, concluíram que a adubação obtém melhores repostas se aplicada aos 21 DAE, e após 28 DAE não apresenta rendimento favorável de grãos.

Farinelli et al. (2006) se preocuparam com o melhor manejo de solo afim de definir o melhor sistema para o cultivo do feijão, plantio direto ou convencional. Em relação ao nutriente nitrogênio, a principal preocupação para a cultura instalada num sistema de plantio direto é a decomposição da palhada e relação $\mathrm{C} / \mathrm{N}$ no processo de imobilização do nitrogênio podendo limitar o desenvolvimento do feijoeiro, especialmente nos estádios iniciais, devido à competição com microrganismo e a grande absorção e extração do $\mathrm{N}$ pela planta. $\mathrm{O}$ experimento foi instalado em Botucatu, no período de verão, plantio em sequeiro, em sucessão de cultura com aveia preta e milheto. Para as parcelas implantadas em plantio convencional foi feita aração e gradagem. As subparcelas foram divididas em cinco doses de adubação nitrogenada: 0, 40, 80, 120 e $160 \mathrm{Kg} / \mathrm{ha}$, utilizando como fonte de $\mathrm{N}$ a ureia em dois anos agrícolas. Notou-se que no segundo ano, os valores de massa de 100 grãos e produtividade cresceram significativamente e Farinelli et al. (2006) acredita que foi devido a sucessão de culturas que contribuiu para a mineralização da matéria orgânica do solo, ou pela eficiência na fixação biológica de $\mathrm{N}$ atmosférico. A linha da produtividade de grãos em relação às doses de $\mathrm{N}$ e crescente para ambos os sistemas de plantio, porem o plantio convencional se destaca em relação ao plantio direto, provavelmente devido à falta de concorrência da decomposição dos restos culturais com o feijoeiro pelo $\mathrm{N}$.

Silveira et al. (2005) também avaliaram a adubação nitrogenada sob plantio direto em sucessão de culturas, testando qual 
opção de planta de cobertura proporcionara melhor produtividade a cultura do feijoeiro. Os tratamentos foram constituídos pelas seguintes culturas de cobertura de solo: braquiária, milho em consorcio com braquiária, guandu, milheto, mombaça, sorgo e estilosantes. Todas essas plantas foram cortadas no mesmo dia. Sessenta dias após o corte, foi semeado o feijão. As parcelas foram constituídas pelas culturas de cobertura e as subparcelas pelas doses de nitrogênio $(0,30$, 60 e $120 \mathrm{Kg} / \mathrm{ha}$ ) sendo metade da dose aplicada aos 15 DAE e o restante 25 DAE. Obteve-se maiores produtividades nas palhadas de milheto e guandu. Porém na palhada de milheto, foi necessário $20 \mathrm{Kg}$ de $\mathrm{N}$ a menos para obter a mesma produtividade de feijão que na palhada do guandu, concluindose que a palhada de milheto restituiu mais $\mathrm{N}$ ao solo do que o guandu. Enquanto que a palhada de milho em consorcio com a braquiária obteve a menor produtividade em qualquer dose de N. Necessitando de maiores doses de $\mathrm{N}$ em cobertura quando o feijoeiro for cultivado pós milho, braquiária, mombaça, sorgo ou estilosantes.

Buscando diminuir custos, melhorar a qualidade do solo e diminuir adubação, Gerlach et al. (2013) também estudaram a possibilidade de se utilizar plantas de cobertura anterior a cultura do feijoeiro. O experimento foi conduzido em Selviria - MS, durante as safras de inverno dos anos 2010 e 2011, utilizando a variedade Perola e em sistema de plantio direto. Foi utilizado blocos ao acaso no sistema fatorial $6 \mathrm{x} 4$, sendo seis coberturas vegetais anteriores ao feijoeiro: Crotalaria juncea, milheto, guandu, Crotalaria juncea + milheto, guandu + milheto e pousio, e quatro doses de $\mathrm{N}$ em cobertura: 0, 30, 60 e $90 \mathrm{Kg} / \mathrm{ha}$ no estádio V4. A semeadura das coberturas vegetais ocorreu em fevereiro e foram dessecadas 90 dias depois. Os resultados obtidos mostraram que nem sempre a maior adubação de $\mathrm{N}$ trará a maior produtividade e que a cobertura de solo com Crotalaria juncea foi a que trouxe maiores produtividades ate mesmo com doses menores de $\mathrm{N}$, seguida do milheto e em terceiro lugar o guandu. A parcela que foi mantida em pousio foi a que obteve menor produtividade mostrando a importância da cobertura vegetal do solo.

Perez et al. (2013) analisaram se o tempo de cultivo em sistema de plantio direto também influenciava a adubação nitrogenada e em qual época de sua aplicação, o N seria melhor utilizado pelo feijoeiro. Concluíram que o tempo em que o solo é cultivado em sistema de plantio direto não influencia a produtividade, a nutrição e a resposta do feijoeiro ao manejo da adubação nitrogenada e que também as maiores produtividades foram constatadas quando o $\mathrm{N}$ foi aplicado em pré-semeadura e em cobertura ou somente em cobertura.

Pacentchuk et al. (2011) testaram a aplicação do nutriente nitrogênio de forma 
foliar em complemento a adubação em cobertura em lavoura de feijão. Utilizou-se um esquema fatorial $3 \times 5$, sendo três estádios para aplicação: V4, R6 e R7 e cinco doses de nitrogênio liquido: $0,4,8,12$ e 16 1/ha. O experimento foi adubado em cobertura com $60 \mathrm{Kg} / \mathrm{ha}$ de $\mathrm{N}$ em V2. Verificou-se que a aplicação feita no estádio R6, ou seja, inicio do florescimento, foi a que obteve melhores resultados tanto em produtividade quanto em massa de mil grãos, e com máxima eficiência técnica na utilização da dose de 8,4 L/ha.

Bueno et al. (2015) também avaliaram o uso de $\mathrm{N}$ na fonte de ureia em cobertura e via foliar. No caso da aplicação em cobertura foram utilizados as dosagens 0,40 e $80 \mathrm{Kg} / \mathrm{ha}$ e no caso da adubação via foliar foram usados 0, 10 e $15 \mathrm{Kg}$ de ureia para 100 litros de água. O sistema de plantio foi o direto, sobre dois tipos de cobertura morta: Crotalaria juncea e Avena strigosa. A ureia em cobertura foi aplicada em uma única dose aos 18-20 DAE e as adubações foliares foram aplicadas 20 DAE, a segunda em pré florada e a última no enchimento de grãos. Concluíram que a adubação via foliar proporciona uma maior número de vagens por planta porém tem pouco influencia sobre a massa de cem grãos e que a concentração de ureia $15 \%$ via foliar foi prejudicial à formação de flores e vagens.

Chidi et al. (2002) também utilizaram ureia via foliar e em cobertura afim de analisar a resposta do feijoeiro a essas aplicações. Concluíram que não houve aumento do número de vagens com o $\mathrm{N}$ aplicado via foliar, diferente do $\mathrm{N}$ aplicado no solo em cobertura que obteve resultado positivo nesse aspecto e que não houve diferença significativa na produtividade na relação adubação em cobertura e adubação foliar.

Soratto et al. (2011) avaliaram a complementação de nitrogênio via foliar em diferentes fases do feijoeiro. Foi aplicado três doses de $\mathrm{N}$ em cobertura: 0, 45 e $90 \mathrm{Kg} / \mathrm{ha}$ e quatro épocas de $\mathrm{N}$ via foliar utilizando-se ureia $10 \%$, sem aplicação foliar, aplicação em R5, em R7 e em R5 e R7. Concluíram que mais uma vez o $\mathrm{N}$ foliar não alterou o número de vagens por planta. Porém essa variável foi proporcionalmente crescente a dosagem de $\mathrm{N}$ usada em cobertura. Quando não foi feita a aplicação em cobertura, houve aumento da massa de cem grãos quando o $\mathrm{N}$ foliar foi aplicado em R5 e R7. Notaram que com a presença da cobertura, independente da dose utilizada, a aplicação via foliar não influenciou a produtividade de grãos.

\section{DESENVOLVIMENTO}

Através de vários experimentos ficou nítida a importância e a eficiência do $\mathrm{N}$ na produção do feijoeiro, evidenciando ser o nitrogênio um nutriente indispensável para a cultura e garantindo maiores produtividades quando fornecido na época e quantidade correta. 
Não foi possível concluir a dose exata que deverá ser aplicada ao feijoeiro, pois esta depende de vários fatores como a cultivar, o solo onde será instalada a cultura, disponibilidade de rizóbios, a cultura anterior, a época do ano, o sistema de plantio, a produtividade esperada e o investimento financeiro do produtor.

Tendo varias formas de se fornecer esse $\mathrm{N}$ a lavoura, ficou evidente que a mais utilizada e mais barata seria a ureia. As perdas por volatilização são muito maiores no sistema de plantio direto do que no convencional, podendo ser minimizada pela incorporação da ureia a $5 \mathrm{~cm}$ de profundidade ou pela irrigação controlada após adubação (LOPES, 1999). Porém deve ser fornecida ate V4, onde a área foliar ainda é pequena, evitando toxidez e também por ser a época onde há melhor absorção e aproveitamento do $\mathrm{N}$ pelo feijoeiro.

Ficou bem claro a necessidade de aumentar a adubação nitrogenada no sistema de plantio direto em relação ao sistema de plantio convencional, devido a concorrência do $\mathrm{N}$ entre o feijoeiro e da decomposição da matéria orgânica.

Em relação à adubação foliar de $\mathrm{N}$, esta não traz resultados significativos quando em substituição a adubação em cobertura. Porém pode ser utilizada como adubação complementar na época da floração da lavoura, garantindo os níveis ideais de $\mathrm{N}$ para que a planta consiga florescer, desenvolver suas vagens e encher os grãos, já que nesta fase o poder de absorção das raízes já são mais limitados.

Em relação à FBN, ainda há necessidade de melhorias afim de desenvolver uma inoculação que substitua completamente a adubação nitrogenada no feijoeiro como já é o caso da soja. A FBN contribui positivamente para o desenvolvimento do feijoeiro, porém não o suficiente para se dispensar as aplicações de N. No entanto, nota-se em alguns trabalhos que doses elevadas de $\mathrm{N}$ atrapalharam $\mathrm{o}$ desenvolvimento dos rizobios comprometendo sua eficácia.

Outro aspecto notado com este estudo, foi a importância e os resultados positivos em relação às plantas de cobertura. Também um grande caminho para a agricultura moderna com a intenção de deixar que a natureza funcione a favor do produtor, conduzindo um solo rico.

Seria de grande importância o aprimoramento dos inoculantes para feijoeiro, para que possa ser cultivado como a soja, sem a adubação de $\mathrm{N}$, dependendo exclusivamente da FBN.

Em relação ao $\mathrm{N}$ líquido ou ureia via foliar, ainda há poucos estudos. Talvez mais experimentos, daria uma certeza melhor em relação a sua eficácia. 


\section{CONSIDERAÇÕES FINAIS}

O nitrogênio é, sem dúvida, limitante a produção de grãos de feijão. Obtém maior efeito quando aplicado no início do desenvolvimento do feijoeiro, no estágio V4. Sua melhor fonte e forma de aplicação seria a ureia via cobertura, por representar o melhor custo benefício por ponto de $\mathrm{N}$, porém aplicada com umidade a fim de evitar sua perca por volatilização, e a forma em que ocorre melhor absorção pelo feijoeiro.

A inoculação deve ser utilizada, porém sem dispensar a adubação nitrogenada em dose adequada para o tipo de manejo da cultura. Vale ressaltar que no caso de sistema de plantio direto, a dosagem de $\mathrm{N}$ aplicada deve ser maior devido à decomposição da matéria orgânica do solo.

\section{REFERÊNCIAS}

ALMEIDA, C.; CARVALHO, M. A. C.; ARF, O.; SÁ, M. E.; BUZETTI, S. Ureia em cobertura e via foliar em feijoeiro. Scentia Agrícola, v. 57, n.2, p.293-298, abr/jun 2000.

AMBROSANO, E. J.; WUTKE, E. B.; AMBROSANO, G. M. B.; BULISANI, E. A.; BORTOLETTO, N.; MARTINS, A.L.M.; PEREIRA, J.C.V.N.A.; SORDI G. Efeito do nitrogênio no cultivo de feijão irrigado no inverno. Scentia Agrícola, Piracicaba, v. 53 n. 23 Mai/Dez. 1996.

BARBOSA, R. M.; COSTA, D. S.; HOMEM, B. F. M.; AS, M. E. Nitrogênio na produção e qualidade de sementes de feijão. Pesquisa
Agropecuária Tropical, Goiânia, v. 41, n. 3, p. $470-474$, jul/set 2011.

BERTOLDO, J. G.; PELISSER, A.; SILVA, R. P.; FAVARETO, R.; OLIVEIRA, L. A. D. Alternativas na fertilização de feijão visando a reduzir a aplicação de $\mathrm{N}$-ureia. Pesquisa Agropecuaria Tropical, Goiania, v. 45, n. 3, p. 348-355, jul/set 2015.

BINOTTI, F. F. S.; ARF, O.; SA, M. E.; BUZETTI, S.; ALVAREZ, A. C. C.; KAMIMURA, K. M. Fontes, doses e modo de aplicação de nitrogênio em feijoeiro no sistema de plantio direto. Bragantina, Campinas, v.68, n.2, p. 473-481, 2009.

BORÉM, A.; CARNEIRO, J. E. S. A Cultura. In: CARNEIRO, J. E.; JÚNIOR, T. J. P.; BORÉM, A. (Ed.). Feijão do plantio à colheita. Viçosa: Ed. UFV, 2015. p.9-15.

BRITO, M. M. P.; MURAOKA, T.; SILVA, E. C. Contribuição da fixação biológica de nitrogênio, fertilizante nitrogenado e nitrogênio do solo no desenvolvimento de feijão e caupi. Bragantina, Campinas, v. 70, n. 1, p. 206-215, 2011.

CALONEGO, J. C.; JUNIOR, E. U. R.; BARBOSA, R. D.; LEITE, G. H. P.; FILHO, H. G. Adubação nitrogenada em cobertura no feijoeiro com suplementação de molibdênio via foliar. Revista Ciência Agronômica, v.41, n.3, p.334-340, jul/set 2010.

CHIDI, S. N.; SORATTO, R. P.; SILVA, T. R. B.; ARF, O.; SÁ, M. E.; BUZETTI, S.

Nitrogênio foliar e em cobertura em feijoeiro irrigado. Acta Scientiarum, Maringá, v. 24, n.5, p. 1391-1395, 2002.

CIF, Centro de Inteligência do Feijão. Disponível em: http://www.cifeijao.com.br

EMBRAPA, Empresa Brasileira de Pesquisas Agropecuária. Sistemas de Produção, 2 ISSN 1679-8869, Versão eletrônica, Jan/2003.

Disponível em: 
http://sistemasdeproducao.cnptia.embrapa.br/ FontesHTML/Feijao/CultivodoFeijoeiro/

FARINELLI, R.; LEMOS L. B.; PENARIOL, F. G.; EGEA, M. M.; GASPAROTO, M. G. Adubação nitrogenada de cobertura no feijoeiro em plantio direto e convencional. Pesquisa Agropecuaria Brasileira, Brasilia, v.41, n.2, p.307-312, fev. 2006.

FILHO, D. F.; XAVIER, M. A.; LEMOS, L. B.; FARINELLI, R. Resposta de cultivares de feijoeiro comum a adubação nitrogenada em sistema de plantio direto. Cientifica, Jaboticabal, v.35, n.2, p.115-121, 2007.

GERLACH, G. A. X.; ARF, O.; CORSINI, D. C. D. C.; SILVA, J. C.; COLETTI, A. J. Analise econômica da produção de feijão em função de doses de nitrogênio e coberturas vegetais. Revista Agropecuária Tropical, Goiânia, v. 43, n 1, p. 42-49, jan/mar 2013.

LOPES, A. S. Recomendações de Calagem e Adubação no Sistema de Plantio Direto. In: RIBEIRO, A.C.; GUIMARÃES, P. T.G.; ALVAREZ V., V. H. (Ed.) Recomendações para o uso de corretivos e fertilizantes em Minas Gerais - $5^{\mathbf{a}}$ Aproximação. Viçosa: Ed. UFV, 1999. p.93-98.

MATOSO, S. C. G.; KUSDRA, J. F. Nodulação e crescimento do feijoeiro em resposta à aplicação de molibdênio e inoculante rizobiano. Revista Brasileira de Engenharia Agrícola e Ambiental, v. 18, n. 6, p. 567-573, 2014.

MEIRA, F. A.; SÁ, M. E.; BUZETTI S.; ARF $O$. Doses e épocas de aplicação de nitrogênio no feijoeiro irrigado cultivado em plantio direto. Pesquisa Agropecuária Brasileira, Brasília, v.40, n.4, p.383-388, abr. 2005.

PACENTCHUK, F.; NOVAKOWISKI, J. H.; NOVAKOWISKI, J. H.; SANDINI, I. E. Nitrogênio complementar via foliar nas culturas do milho, soja e feijão: doses e estádios fenológicos de aplicação. Revista Plantio Direto - edição 142/143 - 2011.
PAULA JÚNIOR, T. J.; VIEIRA, R. F.; TEIXEIRA, H.; JÚNIOR, M. L.; WENDLAND, A. Doenças do Feijoeiro: estratégias integradas de manejo. In: CARNEIRO, J. E.; JÚNIOR, T. J. P.; BORÉM, A. (Ed.). Feijão do plantio à colheita. Viçosa: Ed. UFV, 2015. p.270-299.

PELEGRIN, R.; MERCANTE, F. M.; OTSUBO, I. M. N.; OTSUBO, A. A. Resposta da cultura do feijoeiro à adubação nitrogenada e à inoculação com rizóbio.

Revista Brasileira de Ciência do Solo, v. 33 p. 2219-226, 2009.

PEREZ, A. A. G.; SORATTO, R. P.; MANZATTO, N. P.; SOUZA, E. F. C. Extração e exportação de nutrientes pelo feijoeiro adubado com nitrogênio, em diferentes tempos de implantação do sistema plantio direto. Revista Brasileira de Ciência do Solo, v. 37 p. 1276-1287, 2013.

QUINTELA, E. D.; BARBOSA, F.R. Manejo de pragas. In: CARNEIRO, J. E.; PAULA JÚNIOR, T. J.; BORÉM, A. (Ed.). Feijão do plantio à colheita. Viçosa: Ed. UFV, 2015. p.242-269.

RIBEIRO, A. C.; GUIMARAES, P. T. G.; ALVAREZ, V. H. Recomendações para o uso de corretivos e fertilizantes em Minas Gerais - 5 Aproximação, Viçosa-MG, 1999.

SALGADO, F. H. M.; SILVA, J.; OLIVEIRA, T. C.; BARROS, H. B.; PASSOS, N. G.; FIDELIS, R. R. Eficiência de genótipos de feijoeiro em resposta a adubação nitrogenada. Pesquisa Agropecuária Tropical, Goiânia, v. 42, n. 4, p. 368-374, out/dez. 2012.

SANTI, A. L.; DUTRA, L. M. C.; MARTIN, T. N.; BONADIMAN R.; BELLE, G. L.; FLORA, L. P. D.; JAUER, A. Adubação nitrogenada na cultura do feijoeiro em plantio convencional. Ciência Rural, Santa Maria, v. 36, n.4, p.1079-1085, jul-ago, 2006. 
SILVEIRA, P. M.; BRAZ A. J. B.;

KLIEMANN H. J.; ZIMMERMANN F. J. P.

Adubação nitrogenada no feijoeiro cultivado sob plantio direto em sucessão de culturas.

Pesquisa Agropecuária Brasileira, Brasília, v. 40, n. 4, p. 377-381, abril 2005.

SANTOS, J. B.; GAVILANES, M. L.;

VIEIRA, R. F.; PINHEIRO, L. R. Botânica.

In: CARNEIRO, J. E.; JÚNIOR, T. J. P.;

BORÉM, A. (Ed.). Feijão do plantio à

colheita. Viçosa: Ed. UFV, 2015. p.37-66.

SORATTO, R. P.; FERNANDES, A. M.;

SOUZA, E. F. C.; SCHLICK, G. D. S.

Produtividade e qualidade dos grãos de feijão em função da aplicação de nitrogênio em cobertura e via foliar. Revista Brasileira de Ciência do Solo, 35:2019-2028, 2011.

VIEIRA, R. F.; LIMA, M. S.; NEVES, J. C. L.; ANDRADE, M. J. B. Adubação. In:

CARNEIRO, J. E.; JÚNIOR, T. J. P.;

BORÉM, A. (Ed.). Feijão do plantio à

colheita. Viçosa: Ed. UFV, 2015. p.145-172. 